\title{
KEANEKARAGAMAN MAKROZOOBENTHOS DI DAERAH ALIRAN SUNGAI (DAS) UNUS KOTA MATARAM
}

\section{DIVERSITY MACROZOOBENTHOS IN THE RIVER BASIN UNUS MATARAM CITY}

\author{
Ari Rahmawati' ${ }^{1)}$, Kusmiyati' ${ }^{2}$, M. Liwa Ilhamdi ${ }^{3)}$ \\ ${ }^{1)}$ Mahasiswa Pendidikan Biologi PMIPA FKIP Universitas Mataran \\ ${ }^{2) 33}$ Dosen Pendidikan Biologi PMIPA FKIP Universitas Mataram \\ Email: arierahmawati016@gmail.com
}

Received: 29 Agustus 2017; Accepted: 5 September 2017

\begin{abstract}
Abstrak. Penelitian ini bertujuan untuk mengetahui keanekaragaman makrozoobenthos yang terdapat didaerah aliran sungai Unus Kota Mataram. Penelitian ini merupakan penelitian dekskriptif eksploratif yang telah dilaksanakan pada bulan Maret-April tahun 2017 di tiga titik lokasi yakni Kelurahan Bertais (bagian hulu), Kelurahan Pagesangan (bagian tengah), dan Kelurahan Tanjung Karang (bagian hilir). Pengambilan sampel dilakukan sebanyak 4 kali pengulangan dalam waktu satu bulan dengan Purposive Sampling Method. Sampel diambil dengan menggunakan ayakan dan jaring makrozoobenthos. Berdasarkan hasil penelitian, ditemukan 29 spesies dengan jumlah individu sebanayak 4196 individu yang termasuk dalam 15 famili yaitu Tubuficidae, Glosiphonidae, Lumbriciidae, Lumbricullidae, Erphobdellidae, Nereidae, Hydrophilidae, Nepidae, Hirudinidae, Dugesiidae, Physidae, Thiaridae, Chironomidae, Ampullariidae dan Poduridae. Hasil perhitungan menunjukkan nilai indeks keanekaragaman (H') makrozoobenthos untuk seluruh jenis diperoleh 2,003 (kategori sedang). Hasil Perhitungan menunjukkan nilai indeks dominanasi (D) makrozoobenthos untuk seluruh jenis yaitu 0,19 (kategori sedang). Hasil perhitungan menunjukkan nilai indeks kemerataan (E) makrozoobenthos di sungai Unus Kota Mataram menunjukkan nilai kemerataan sebesar 0,59 (sedang).
\end{abstract}

Kata Kunci: Keanekaragaman, Makrozoobenthos, Daerah Aliran Sungai Unus.

\begin{abstract}
The purpose of this research to determine the diversity of macrozoobenthos contained in the river basin Unus Mataram city. This research is an explorative descriptive research that has been conducted in March - April of 2017 at three points of location are, Bertais (Upstream), Pagesangan (midle), and Tanjung Karang (downsteram) sub-districts. Sampling is done 4 times repetition within one month with purposive sampling method. Samples were obtained using sieve and macrozoobenthos nets. It was found 29 species with 4196 individuals included in the 15 families which were Tubuficidae, Glosiphonidae, Lumbriciidae, Lumbricullidae, Erphobdellidae, Nereidae, Hydrophilidae, Nepidae, Hirudinidae, Dugesiidae, Physidae, Thiaridae, Chironomidae, Ampullariidae and Poduridae. The calculation result showed that the value of diversity index ( $\left.\mathrm{H}^{\prime}\right)$ was 2.003 (medium category) and macrozoobenthos dominance index (D) value for all types was 0.19 (medium category). The fairness municipality indicates a value of 0.59 (medium category).
\end{abstract}

Keyword: Diversity, Macrozoobenthos, Unus Watershed (DAS).

\section{PENDAHULUAN}

Kondisi geografis Indonesia memungkinkan banyak ditemukannya jenis makrozoobenthos, karena Indonesia memiliki iklim tropis dengan temperatur tinggi dan relatif tetap sepanjang tahun, serta kelembaban dan curah hujan yang tinggi. Kekayaan keanekaragaman hayati Indonesia tersebar di berbagai kawasan ekosistem perairan.

Anonim [1], menyatakan daerah aliran sungai Unus terbentang diantara $-08^{0} 35^{\prime} 07^{\prime \prime} \mathrm{s} / \mathrm{d}$ 08037'29" LS dan $122^{\circ} 04$ '21" s/d 122009'54" BT. Sungai Unus memiliki panjang 21,53 km dan luas
$38,560 \mathrm{~km}^{2}$, berhulu di Gunung Buanmangge $(+2,895 \mathrm{~m})$, dalam pengalirannya menuju Selat Lombok dengan melintasi Kota Mataram yang merupakan Ibu Kota Provinsi Nusa Tenggara Barat. Sungai Unus merupakan suatu ekosistem yang banyak menyimpan keanekaragaman hayati, salah satunya adalah makrozoobenthos. Keberadaan makrozoobenthos dalam ekosistem sungai memiliki peran yang sangat penting.

Makrozoobenthos pada rantai makanan merupakan konsumen tingkat pertama yaitu membantu mikroorganisme pengurai bahan organik kompleks menjadi lebih sederhana 
sehingga mikroorganisme dapat menguraikan dengan cepat dan mudah. sungai merupakan ekosistem yang mempunyai peranan sangat penting bagi kelangsungan hidup makhluk hidup yang ada disekitar lingkungan perairan. Berbagai macam aktivitas dapat dilakukan dalam pemanfaatan sungai, diantaranya keperluan industri, rumah tangga, transportasi, perikanan dan lain sebagainya [2].

$$
\text { Fikri [3] }
$$

[3] mengungkapkan makrozoobenthos merupakan invertebrata yang dapat dilihat dengan mata telanjang, hidup di dalam dan sektitar bebatuan di dasar perairan. Selain itu makrozoobenthos juga dapat didefinisikan sebagai hewan invertebrata yang hidup di dalam atau pada sedimen atau substrat lain, berukuran besar dan tertahan pada ayakan berukuran $0.595 \mathrm{~mm}$.

Degradasi dan penurunan daya dukung lingkungan, dapat mengubah struktur dan fungsi dari komunitas yang ada dan perubahan yang terjadi bergantung pada kemampuan toleransi dari masing - masing spesies penyusunnya. Tiap spesies mempunyai ambang toleransi terhadap pencemaran yang berbeda dan akan berakibat pada kemampuan spesies untuk melakukan kompetisi pada suatu lingkungan [4].

Menurunnya kualitas air dan berubahnya sifat - sifat fisika - kimia akibat pencemaran yang terjadi akan membeayangkan bagi kehidupan organisme perairan terutama makrozoobenthos, karena sifat hidupnya yang relatif menetap di dasar perairan. Perubahan terhadap struktur komunitas organisme perairan akibat pencemaran berdampak pula akibat terhadap stabilitas ekosistem dimana organisme perairan tersebut tinggal. Komunitas benthos dipengaruhi oleh 14 faktor fisika-kimia perairan, 8 diantaranya termasuk penentu kriteria kualitas perairan yaitu kesadahan, pH, bahan beracun, oksigen terlarut, suhu, kekeruhan, nutrien dan padatan tersuspensi [5].

Berdasarkan uraian di atas maka perlu dilakukan penelitian tentang keanekaragaman makrozoobenthos, yang bertujuan untuk mengetahui keanekaragaman makrozoobenthos yang berada di daerah aliran sungai (DAS) Unus Kota Mataram.

\section{METODE PENELITIAN}

Bahan - bahan yang digunakan dalam penelitian ini yaitu formalin $4 \%$, aquadest, kertas label dan kantong plastik. Sedangkan alat - alat yang digunakan yaitu jaring makrozoobenthos, ayakan, lux meter, $\mathrm{pH}$ meter, termometer digital, kamera, ember, kaca pembesar, pinset dan buku identifikasi.
Penelitian ini dilakukan pada bulan Maret - April 2017 di daerah aliran sungai (DAS) Unus yang melintasi Kota Mataram. Proses pengambilan data ini mengunakan metode survei secara puposive. Pengambilan sampel dilakukan pada tiga titik stasiun yakni bagian hulu, tengah dan hilir. Setiap staisun dibagi menjadi tiga titik area yakni pinggri kanan, tengah dan pinggir kiri. Sampel diambil dengan menggunakan jaring makrozoobenthos dan ayakan. Sampel yang berhasil ditangkap dikumpulkan dalam kantong plastik berisikan formalin dan diberi label sesuai titik pengambilan sampel. Sampel yang berhasil dikumpulkan selanjtunya diidentifikasi di Laboratorium Biologi FKIP Universitas Mataram, dengan buku pnaduan identifikasi Daru Setyo Rini (2011) dan Rohana Long (2002).

Data hasil penegamatan makrozoobenthos yang diperoleh kemuadian dianalisis secara kualitatif dan kuantitatif. Analisis data secara kaulitatif meliputi analisis secar deskriptif komposisis makrozoobenthos di daerah aliran sungai (DAS) Unus Koata Mataram. Analisis kuantitatif meliputi indeks dominansi makrozoobenthos dan indeks keanekeragaman jenis makrozoobenthos adalah dengan rumus indeks keanekaragaman jenis Shannon-Wiener dari Michael (1994) yang tercantum dalam Irmala [6].

$$
\begin{aligned}
H^{\prime} & =-\sum\left(\frac{n i}{N}\right) \ln \left(\frac{n i}{N}\right) \\
& =-\sum P i \ln P i
\end{aligned}
$$

Dimana:

$H^{\prime} \quad=$ Indeks keanekaragaman jenis

ni = Jumlah individu spesies

$\mathrm{Pi} \quad=$ Proporsi spesies ke-i

In $\quad=$ Logaritma natur

$\Sigma \quad=$ Jumlah

$\mathrm{N}=$ Jumlah total individu

\section{HASIL PENELITIAN}

\section{Spesies - Spesies Makrozoobenthos}

Hasil penelitian yang telah dilakuakan di daerah aliran sungai (DAS) Unus Kota Mataram ditemukan 29 spesies dengan jumlah 4196 individu yang termasuk dalam 15 famili yaitu Tubuficidae, Glosiphonidae, Lumbriciidae, Lumbricullidae, Erphobdellidae, Nereidae, Hydrophilidae, Nepidae, Hirudinidae, Dugesiidae, Physidae, Thiaridae, Chironomidae, Ampullariidae dan Poduridae. Lebih jelasnya terangkum pada Tabel 1. 
Tabel 1. Spesies - Spesies Makrozoobenthos di Daerah Aliran Sungai Unus Kota Mataram

\begin{tabular}{|c|c|c|c|c|}
\hline No & Ordo & Famili & Spesies & $\begin{array}{c}\text { Total } \\
\text { Individu }\end{array}$ \\
\hline \multirow[t]{2}{*}{1} & Lumbricullida & Lumbriculidae & Lumbriculus sp & 115 \\
\hline & & Lumbriciidae & Fam : Lumbricidae & 47 \\
\hline \multirow[t]{2}{*}{2} & Haplotaxida & Tubificidae & Tubifex sp. & 1095 \\
\hline & & & Branchiura sowerbyi & 804 \\
\hline \multirow[t]{7}{*}{3} & Rhyncobdellida & Glossiphonidae & Glossiphonia sp.1 & 7 \\
\hline & & & Glossiphonia sp.2 & 16 \\
\hline & & & Glossiphonia sp.3 & 3 \\
\hline & & & Glossiphonia sp.4 & 5 \\
\hline & & & Helobdella stagnalis & 1223 \\
\hline & & & Helobdella chavinensis & 13 \\
\hline & & & Helobdella austinensis & 16 \\
\hline 4 & Hirudinida & Hirudinidae & Hirudo sp. & 4 \\
\hline \multirow[t]{2}{*}{5} & Pharyngobdellida & Erpobdellidae & Mooreobdella sp. & 108 \\
\hline & & & Erpobdela sp. & 8 \\
\hline 6 & Phyllodocida & Nereidae & Nereis sp. & 2 \\
\hline 7 & Diptera & Chironomidae & Chironomus sp. & 72 \\
\hline 8 & Coleoptera & Hydrophilidae & Hydrophilus sp. & 2 \\
\hline 9 & Hemiptera & Nepidae & Fam: Nepidae & 2 \\
\hline 10 & Collembola & Poduridae & Podura aquatica & 295 \\
\hline 11 & Pulmonata & Physidae & Physa sp. & 6 \\
\hline \multirow[t]{8}{*}{12} & Prosobranchiata & Thiaridae & Melanoides sp.1 & 6 \\
\hline & & & Melanoides sp.2 & 21 \\
\hline & & & Melanoides sp.3 & 25 \\
\hline & & & Melanoides granifera & 55 \\
\hline & & & Melanoides turbecullata & 31 \\
\hline & & & Melanoides turricula & 23 \\
\hline & & & Thiara scabra & 91 \\
\hline & & Ampullariidae & Pomacea sp. & 87 \\
\hline 13 & Tricladida & Dugesiidae & Dugesia sp. & 15 \\
\hline
\end{tabular}

Tabel 2. Kondisi Lingkungan Perairan Sungai Unus Kota Mataram

\begin{tabular}{llrrrrr}
\hline \multirow{2}{*}{ No } & Parameter & \multicolumn{3}{c}{ Stasiun } & \multirow{2}{*}{ Jumlah } & \multirow{2}{*}{ Rerata } \\
\cline { 3 - 5 } & & \multicolumn{1}{c}{ I } & \multicolumn{1}{c}{ II } & \multicolumn{1}{c}{ III } & & \\
\hline 1 & Suhu Air & 25,40 & 26,10 & 28,80 & 80,30 & 26,76 \\
2 & pH Air & 7,37 & 7,13 & 7,24 & 21,74 & 7,24 \\
3 & Kecepatan Arus & 0,26 & 0,23 & 0,22 & 0,71 & 0,23 \\
4 & Intensitas Cahaya & 638,20 & 585,50 & 710,8 & 1934,5 & 644,83 \\
\hline
\end{tabular}




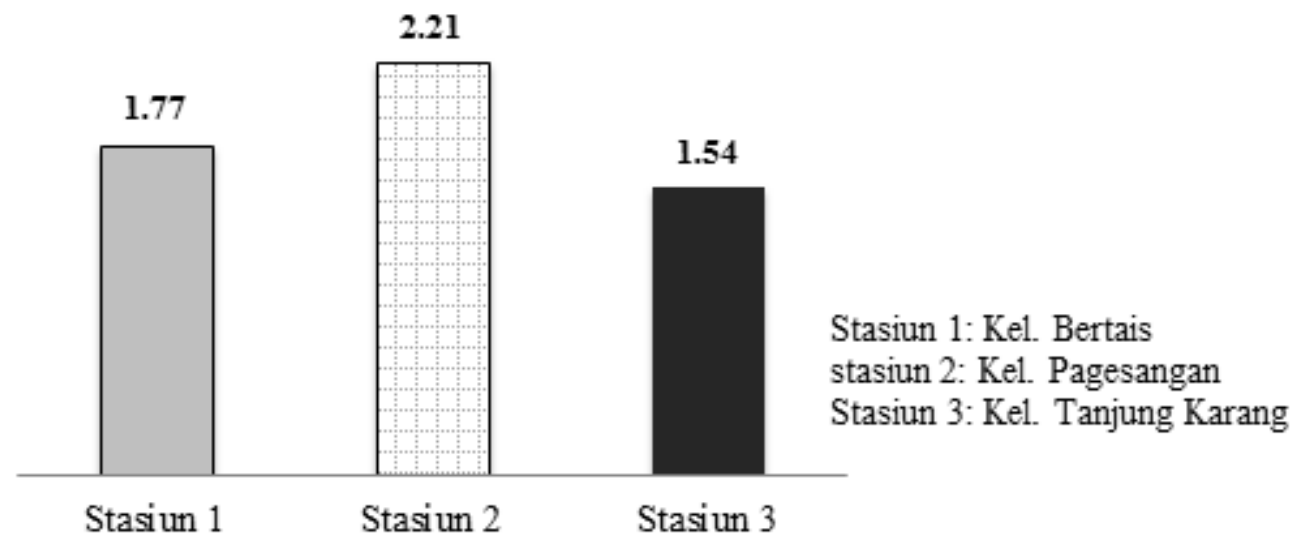

Gambar 1. Nilai Indeks Keanekaragaman Makrozoobenthos Sungai Unus Kota Mataram

Penelitian tentang keanekaragaman makrozoobenthos telah banyak dilakukan di perairan (sungai). dari data tersebut menunjukkan bahwa jenis lintah memiliki nilai kehadiran yang tertinggi dari semua jenis makrozoobenthos yang berahsil dikumpulkan. Tinggi rendahnya kehadirannya diketahui bahwa tidak semua jenis makrozoobenthos memiliki kemampuan bertahan hidupa atau toleransi pada tempat yang sama.

\section{Indeks Keanekaragaman Makrozoobenthos di Sungai Unus Kota Mataram}

Keanekaragaman spesies makrozoobenthos yang terdapat di daerah aliran sungai (DAS) Unus Kota Mataram memiliki nilai indeks keanekaragaman sebesar 2,003 (kategori sedang), sedangkan dari masing masing staisun penelitiatian menunjukkan nilai indeks keanekaragaman yang berbeda - beda. Hasil perhitungan menunjukkan nilai indeks keanekaragaman yang tertinggi terdapat pada staisun 2 yakni sebesar 2,21 dan nilai indeks keanekaragaman yang terendah terdapat pada staisun 3 yakni 1,54 (Gambar 1). Nilai indeks keanekaragaman yang sedang mungkin disebabkan oleh beberapa fakto - faktor fisika kimia perairan masih berada dalam batas ambang sehingga dapat mendukung kehidupan dan pertumbuhan dari makrozoobenthos.

Indeks Dominansi Makrozoobenthos di Sungai Unus Kota Mataram

Hasil penelitian menunjukkan bahwa nilai indeks dominansi seluruh jenis makrozoobenthos di perairan sungai Unus Kota Mataram adalah 0,19 (kategori sedang). Menurut Odum [7], nilai indeks dominansi berkisar antara 1 - 0 . Semakin mendekati satu, maka semakin tinggi dominansi spesies tertentu, sebaliknya bila nilai mendekati nol berarti tidak ada jenis yang mendominansi. Dominansi dinyatakan sebagai kekayaan jenis suatu komunitas serta keseimbangan individu setiap jenis.

\section{Kondisi Lingkungan di Sungai Unus Kota Mataram}

Berlangsungnya kehidupan biota air di suatu perairan (sungai) sangat bergantung pada kondisi lingkungan. Sebagaiamana dikeatuhi bahwa tidak semua biota air akan dapat bertahan didup pada kondisi lingkungan yangsama karena memiliki nilai toleransi yang berbeda beda (Tabel 2). Hasil penenlitian menunjukkan bahwa $\mathrm{pH}$ air di sungai Unus sebesar 7,24 yang menandaakan nilai $\mathrm{pH}$ masih normal. sebagaimana dalam Simamora [9] kehidupan dalam air masih dapat bertahan apabila perairan kisaran $\mathrm{Ph} 7-8,5$.

Suhu air perairan sungai Unus menunjukkan nilai $26^{\circ} \mathrm{C}$ yang menunjukkan suhu air yang masih normal. Hal ini sesuai dengan pernyataan Fikri [3], bahwa suhu yang ditolelir oleh jenis makrozoobenthos adalah dalam kehidupannya berkisar antara $25^{\circ} \mathrm{C}-$ $53^{\circ} \mathrm{C}$. intensitas cahaya perairan sungai Unus menunjukkan intensitas cahaya yang masih dapat mendukung keberlangsungan hidup makrozoobenthos yakni sebesar 644,8 lux.

Kecepatan arus ditentukan oleh bagaimana komposisi perairan tersebut. Hasil pengukuran kecepatan arus menunjukkan bahwa kecepatan arus yang terdapat di perairan sungai Unus Kota Mataram adalah sebesar 0,23 m/dt. Hasil pengamatan pada masing - masing stasiun penelitian menunjukkan bahwa tumbuhan yang berada di sekitar perairan sungai Unus adalah berupa Ipomea batatas, Ipomea aquatica, Graminae, Colocasia sp., dan Eichhornia crassipe. 


\section{KESIMPULAN}

Berdasarkan hasil penelitian dapat disimpulkan bahwaIndeks keanekaragaman makrozoobenthos di daerah aliran sungai Unus Kota Mataram tegolong sedang $\left(\mathrm{H}^{\prime}=2,003\right)$ dan indeks dominansi makrozoobenthos tergolong sedang $(\mathrm{D}=0,19)$.

\section{DAFTAR PUSTAKA}

[1] Anonim. 2011. Katalog Sungai Unus (Wilayah Sungai Pulau Lombok). Mataram: BWS NT 1.

[2] Setiawan, D. 2008. Struktur Komunitas Makrozoobenthos sebagai Bioindikator Kualitas Lingkungan Perairan Hilir Sungai Musi. Thesis. Sekolah Pascasarjana Institut Pertanian Bogor.

[3] Fikri, N. 2014. Keanekaragaman dan Kelimpahan Makrozoobentos di Pantai Kartika Jaya Kecamatan Patebon Kabupaten Kendal. Skripsi. Surakarta: Universitas Muhammadiyah Surakarta.

[4] Arisandi, P. 2012. Pengukuran Kualitas Air Hulu Daerah Aliran Sungai Kali Brantas berdasarkan Keragaman Taksa Ephemeroptera, Plecoptera, dan Tricoptera. Prosiding Seminar Nasional Kimia Unesa: 298-309 ISBN 978-979028-550-7.

[5] Yusuf, M. 2011. Kajian Dampak Pencemaran terhadap Kualitas Lingkungan Perairan dan Struktur Komunitas Organisme Makrozoobenthos di Muara Sungai Babon, Semarang. Jurnal Buletin Oseanografi Marina 1: 27-35.

[6] Rahim, I. 2015. Komunitas Gastripoda dan Bivalvia di Daerah Pasang Surut Pulau Bedil Kabupaten Sumbawa serta Pengembangannya sebagai Media Pembelajaran. Skripsi. Mataram: Universitas Mataram.

[8] Odum P.E. 1993. Dasar - Dasar Ekologi. Terjemahan Tjahjono Samingan. Edisi Ketiga. Yogyakarta: UGM Press.

[9] Simamora, Dahlia R. 2009. Studi Keanekaragaman Mkarozoobenthos di Aliran Sungai Padang Kota Tebing Tinggi. Skripsi. Medan: Universitas Sumatera Utara. 